\title{
The Effect of Organizational Change on Mental Health, by Examining the Moderator Role of Support and Job Control
}

\author{
Alireza Aghigi', Mahdi Rezaee Tale ${ }^{2 *}$, Ali Lahotian ${ }^{3}$, Saied Shahabinia $^{4}$
}

1. Department of Management, Payam-e Noor University (PNU), Tehran, Iran

2. Master of Public Administration, Alvand Higher Education Institute, Tehran, Iran

3. $\mathrm{PhD}$ in Public Administration, University of Tehran

4. Department of Management, Payame Noor University (PNU), Tehran, Iran

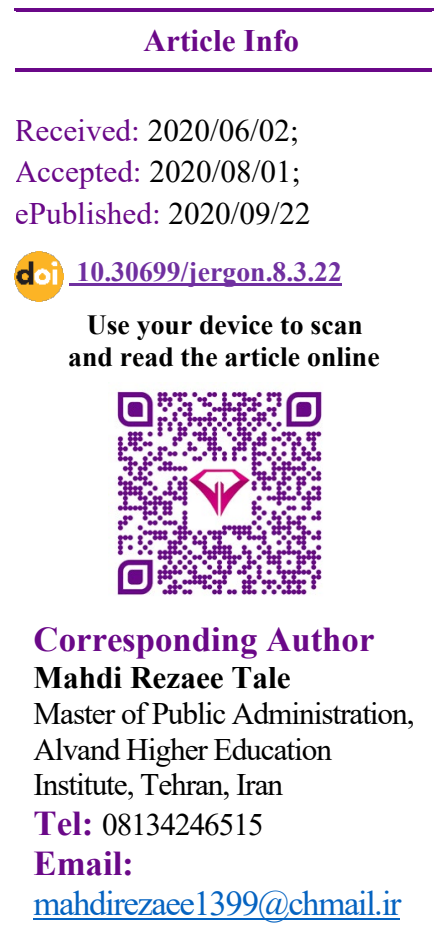

\section{ABSTRACT}

Background and Objectives: The present study seeks to explain the effect of organizational change on employees' mental health with respect to the moderating role of job support and control.

Methods: This method is descriptive and correlational. The statistical population of the study was the staff of Farshchian Sina Hospital in Hamadan, Iran, a total number of 200 people. Sample size was determined based on Morgan table to be 132 people which were randomly selected. Standard questionnaires of organizational change, general health, job support and job control were used to measure the variables. Data analysis was performed using SPSS 23 and smart SPLS version 2.

Results: Findings indicated that $43 \%$ of employees' mental health changes are explained by organizational change. Organizational change, considering the moderating effect of job support, has a positive effect on employees' mental health. The standardized coefficient between the two variables showed that $24 \%$ of mental health changes are explained by organizational change, taking into account the adjustment effect of job support. Organizational change, considering the moderating effect of job control, also has a positive effect on the mental health of employees. The standardized coefficient between the two variables also showed that $29 \%$ of mental health changes are explained by organizational change, considering the moderating effect of job control. Therefore, organizational change has a positive effect on the mental health of Farshchian Hospital staff in Hamadan.

Conclusion: The results of the research indicated that making organizational changes in Farshchian Hospital in Hamadan, considering the supportive role and control of managers, improves the mental health of employees.

Keywords: Organizational change, Mental health, Support control, Job control

Copyright (C) 2020, This is an original open-access article distributed under the terms of the Creative Commons Attribution-noncommercial 4.0 International License which permits copy and redistribute of the material just in noncommercial usages with proper citation.

\section{How to Cite This Article:}

Aghighi A, Rezaeetale M, Lahotian A, Shahabinia S. The Effect of Organizational Change on Mental Health, by Examining the Moderator Role of Support and Job Control. Iran J Ergon. 2020; 8 (3):22-35 
بررسى تأثير تغيير سازمانى بر سلامت روان كاركنان با نقش تعديلكَر حمايت و كنترل شغلى (مورد مطالعه: بيمارستان فرشجيان (سينا) همدان)

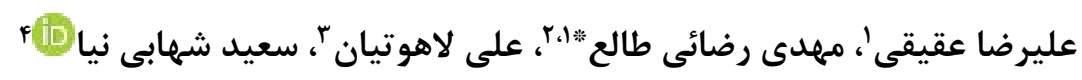

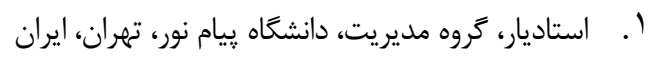

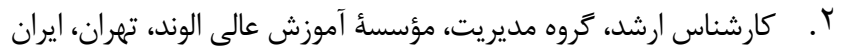

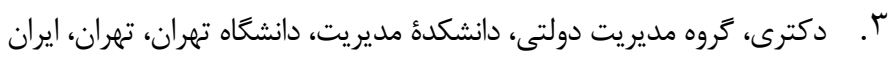

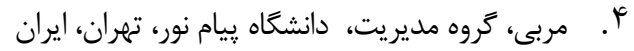

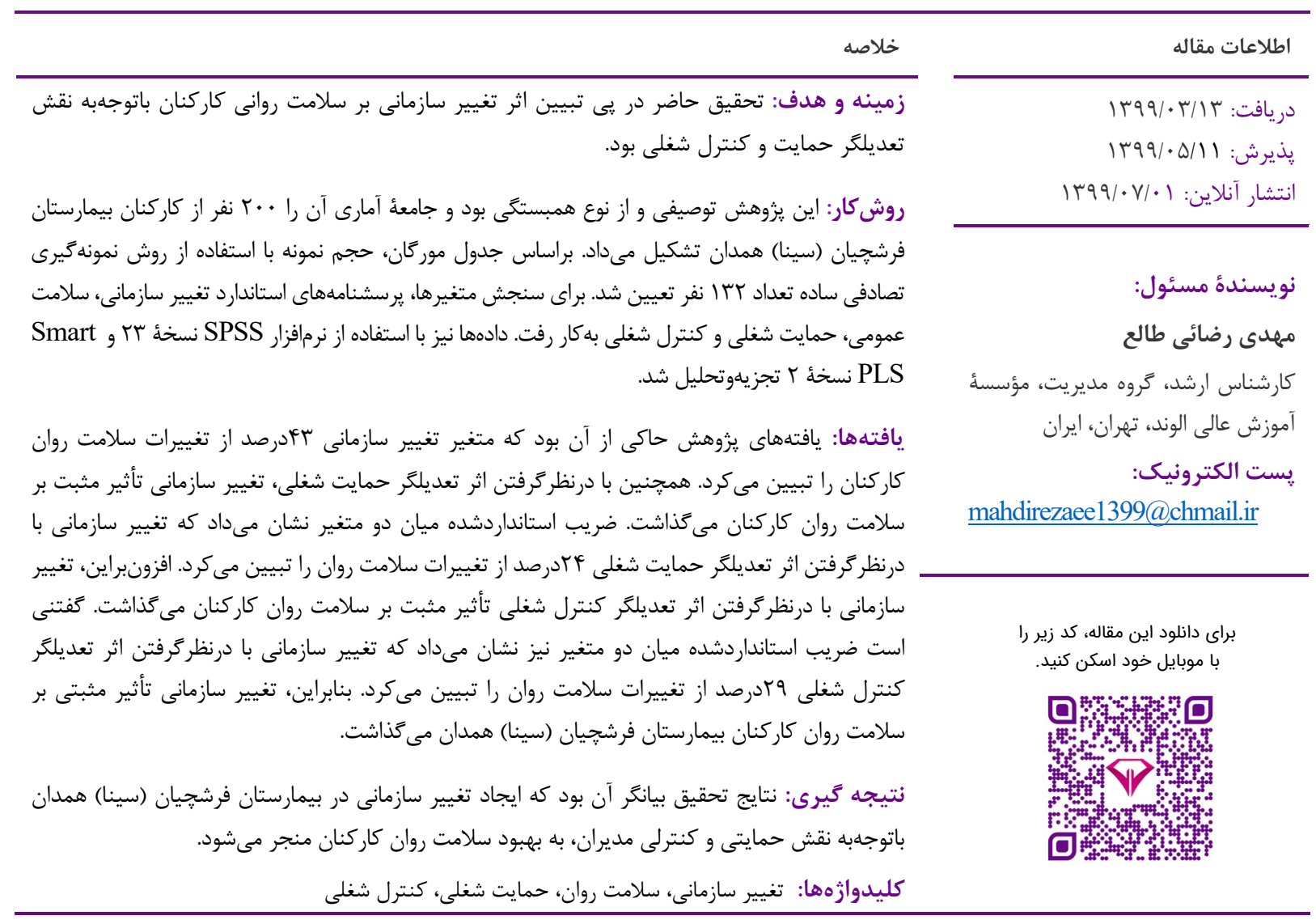

برخورد كند. بهعبارتِديخر، افراد داراى سلامت روان در عين كسب

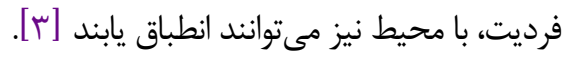
يكى از هدفهاى مهمم نظام سلامت در هر كشور، تأمين و حفظ إنظ

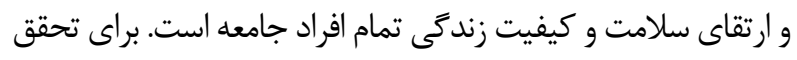

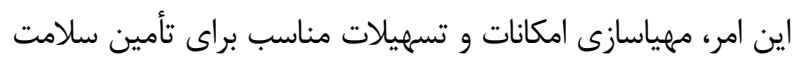

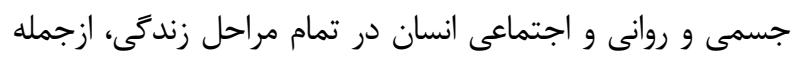

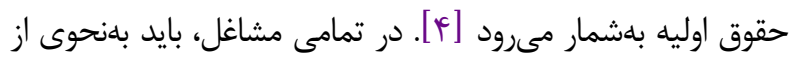

سلامت بلعنوان يكى از نيازهاى اساسى انسان، در توسعهُ پِايدار

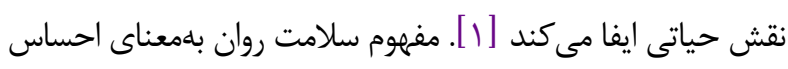

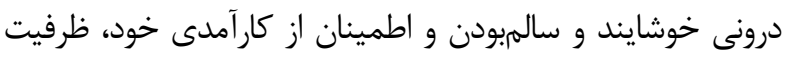

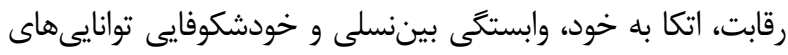

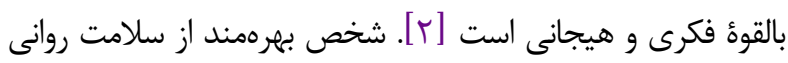

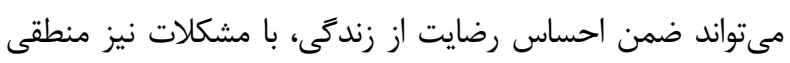


كارى كه جوّ حمايتى دارند و كنترل شغلى را فراهمم مى كنند، ممكن

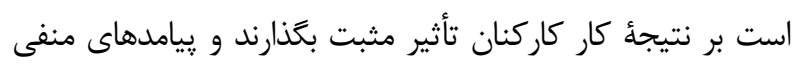

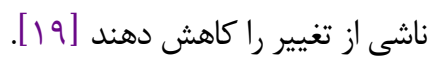

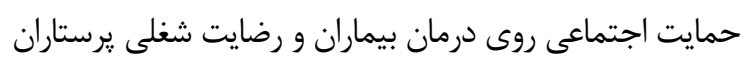

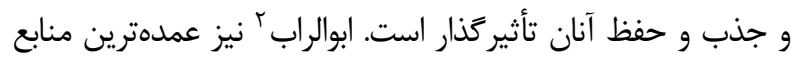

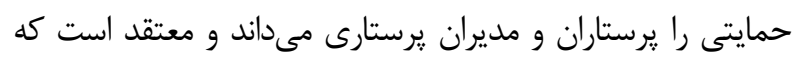

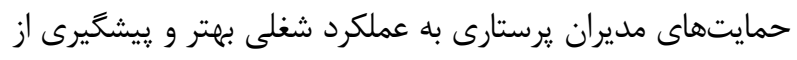

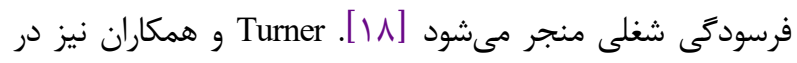

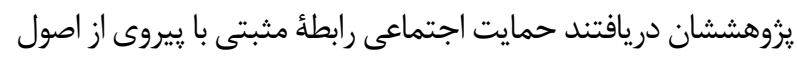

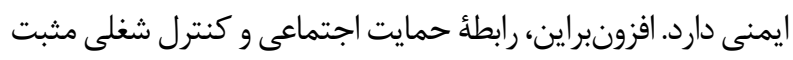

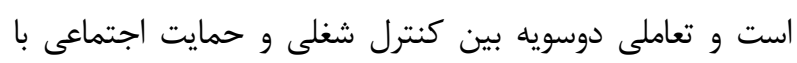

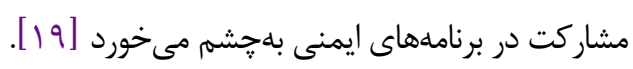

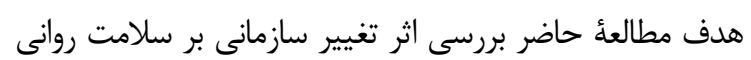

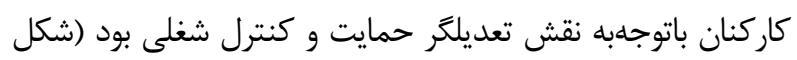

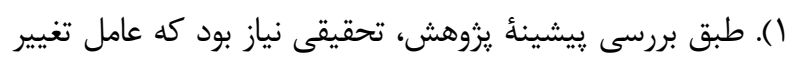

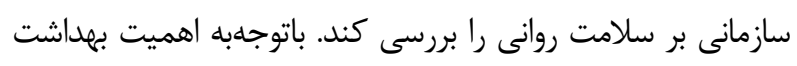

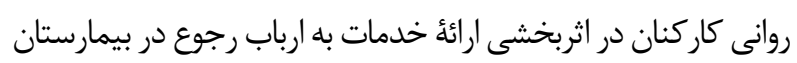

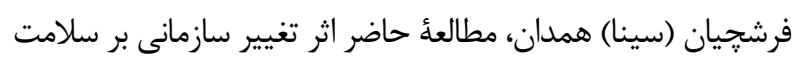

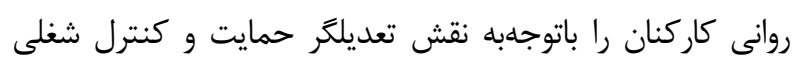

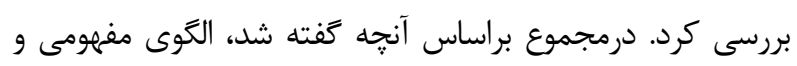

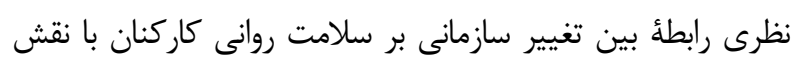

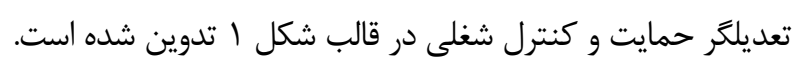

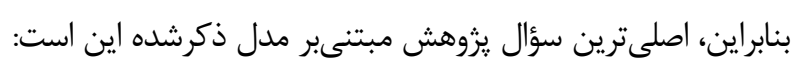

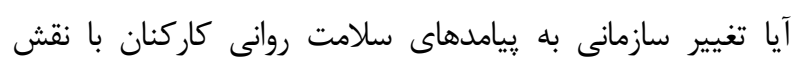

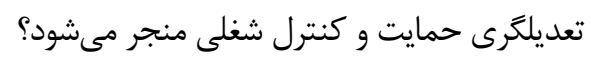

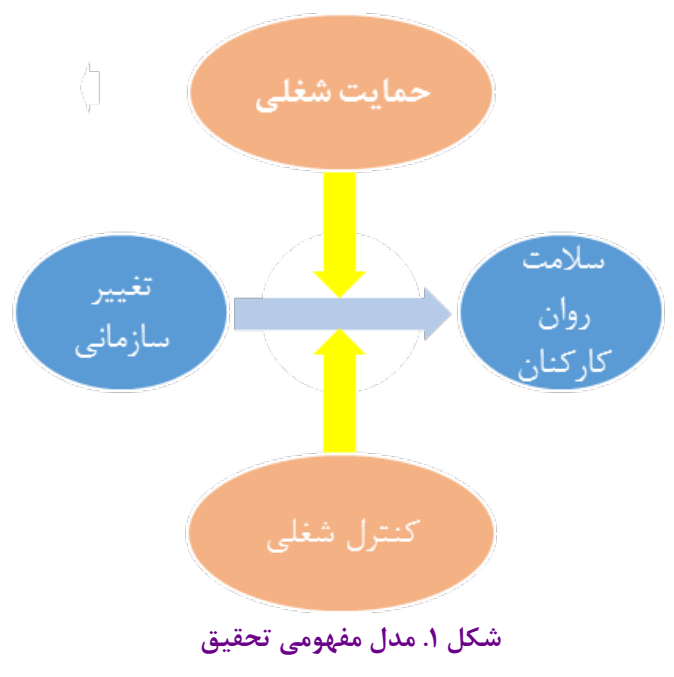

${ }^{2}$ Abualrub
تأثير گذارى فشارهاى كارى روى روان كاركنان خود جلوكيرى كرد؛

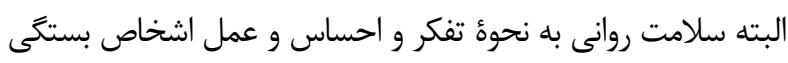

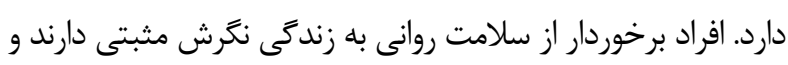

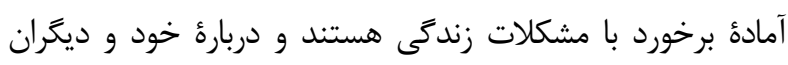
احساس خوبى دارند [ه].

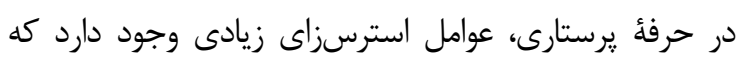

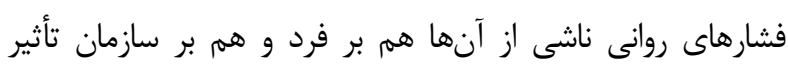

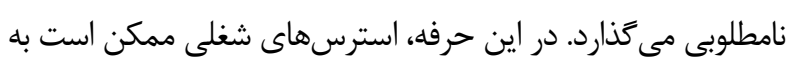

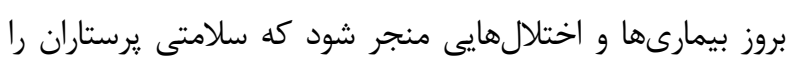

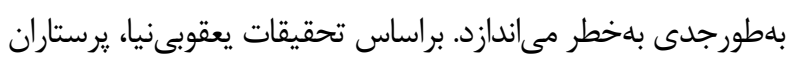

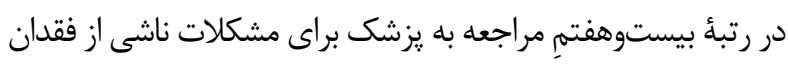

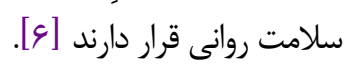

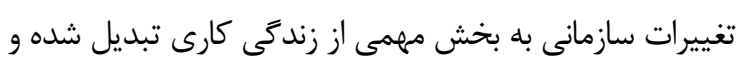

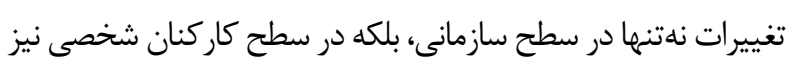

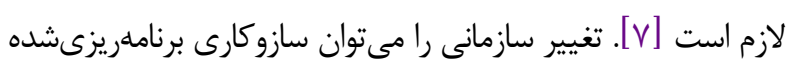

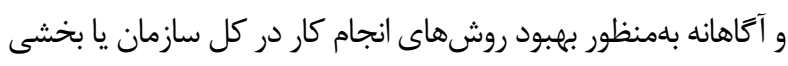

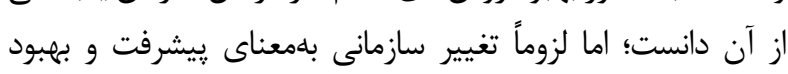

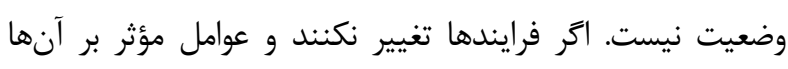

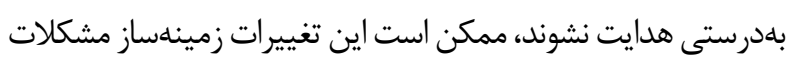

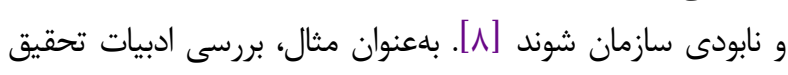

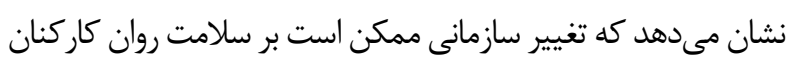

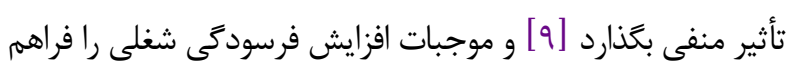

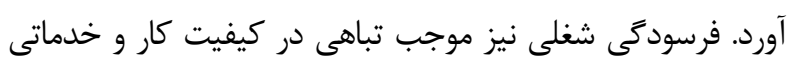

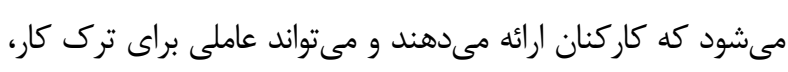

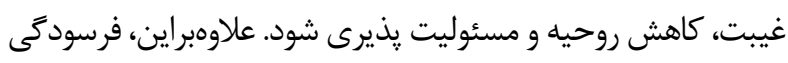

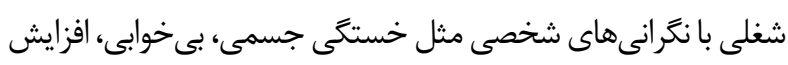

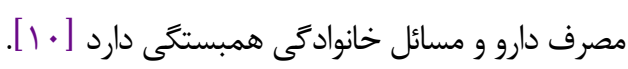

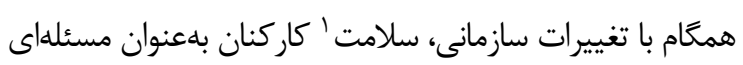

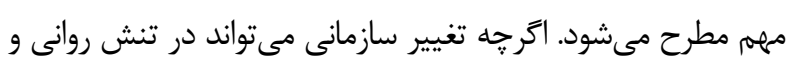

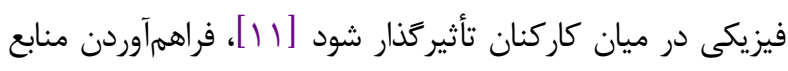

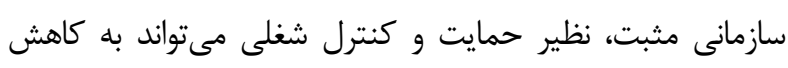

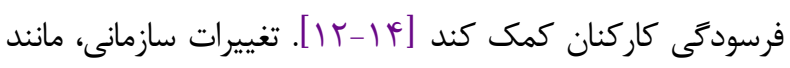

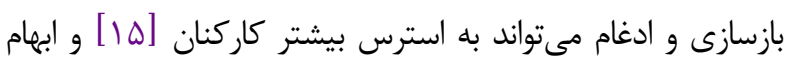

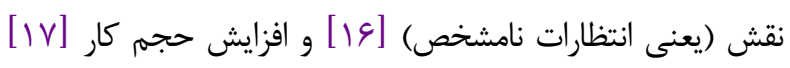

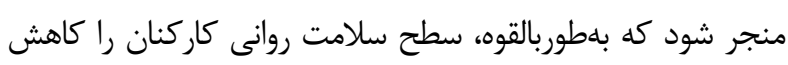

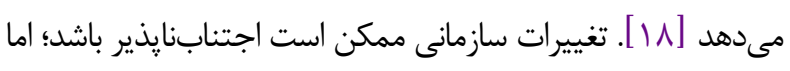

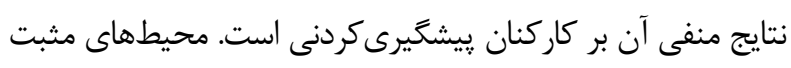

${ }^{1}$ Health 
سلامت عمومى؛ ז. اضطراب؛ ؟. اختلال عملكرد اجتماعى؛ f. أ. روش كار

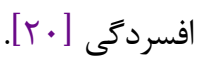

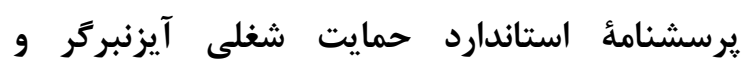

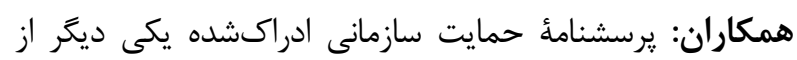

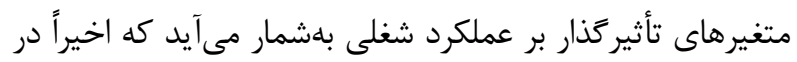

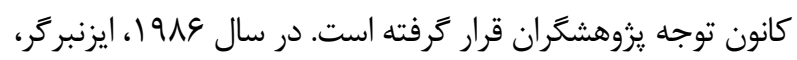
هانتينگتون، هاتكينسون و سوا نخستينبار ايده حمايت سازمانى

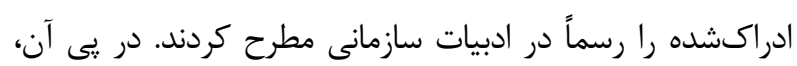

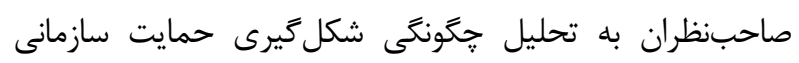

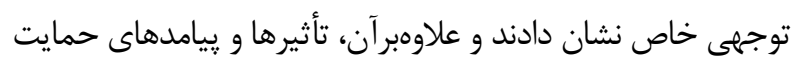

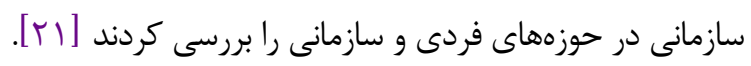

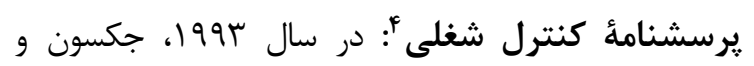

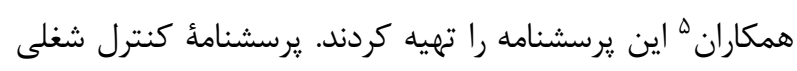

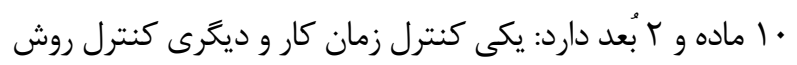

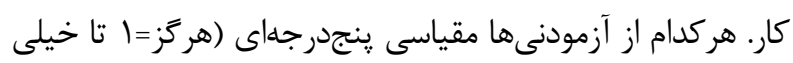

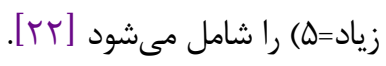

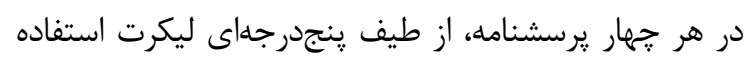
شده است. جدول ا توزيع كويههاى يرسشنامهها را نشان مى ئدهد.

تحقيق حاضر ازلحاظ هدف، كاربردى و ازلحاظ روش، توصيفى

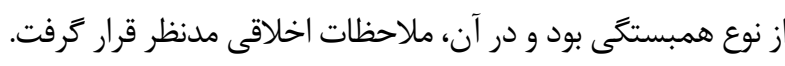

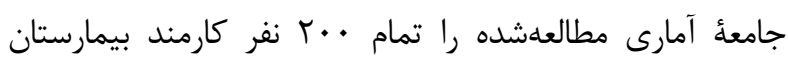

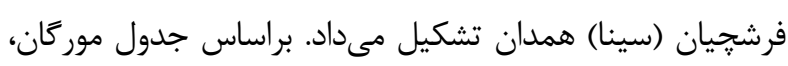

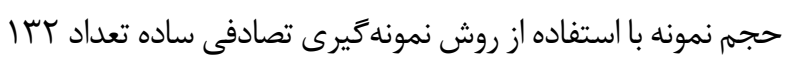

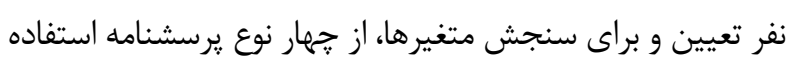

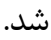

يرسشنامهُ تغيير سازمانى: اين يرسشنامه از لها سؤال

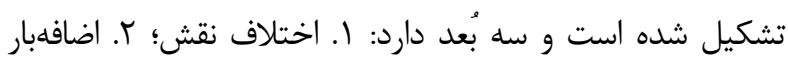

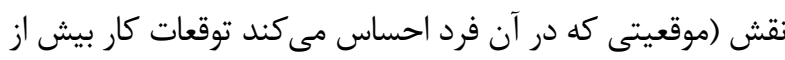

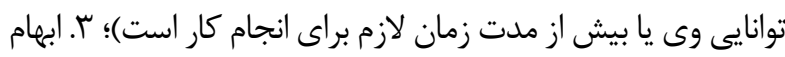

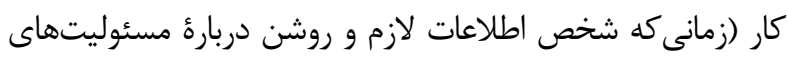

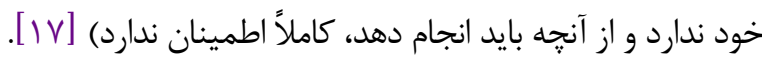

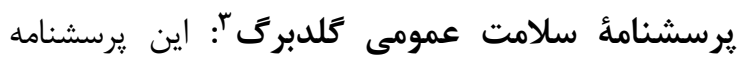

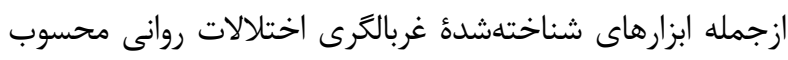

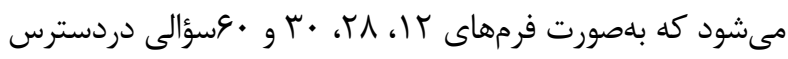

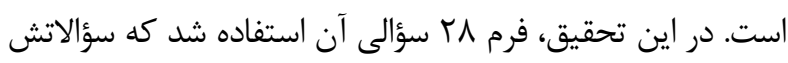

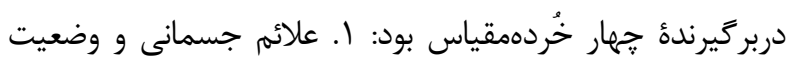

جدول ا. رتباط سؤالات با متغيرهاى تحقيق

\begin{tabular}{|c|c|c|}
\hline تعداد سؤال & عش & متغير \\
\hline 4 & ابهام نقش & \multirow{3}{*}{ تغيير سازمانى } \\
\hline$\Delta$ & اضافهبار نقش & \\
\hline r & تعارض نقش & \\
\hline V & علائم جسمانى & \multirow{4}{*}{ سلامت روانى } \\
\hline V & اضطراب & \\
\hline v & اختلال عملكرد اجتماعى & \\
\hline V & افسردگى & \\
\hline ir & حمايت شغلى & حمايت شغلى \\
\hline 9 & كنترل روش & \multirow[b]{2}{*}{ كنترل شغلى } \\
\hline f & كنترل زمان & \\
\hline
\end{tabular}

در اين يزوهش، اين دو شاخص بلتفكيك بررسى شد. نتايج نشان

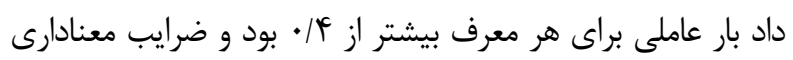

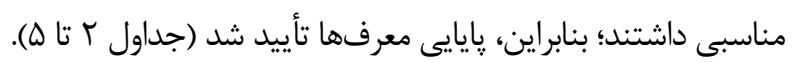

${ }^{6}$. Fornell \& Larcker
در اين تحقيق، روايى سازء ابزار با استفاده از تحليل عامل تأييدى

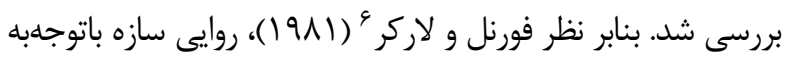

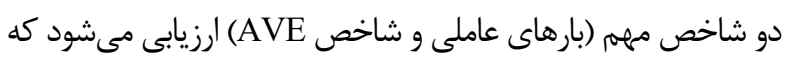

\footnotetext{
${ }^{3}$ Goldberg General Health Questioner

${ }^{4}$ Job control scale

${ }^{5}$ Jackson et al
} 
جدول r. نتايج تحليل عاملى تأييدى متغير تغيير سازمانى

\begin{tabular}{|c|c|c|c|}
\hline t-value & بار عاملى & سؤال & متغير \\
\hline FI.VITQHK & $\cdot . \vee q \vee r \cdot \Delta$ & 1 & \multirow{6}{*}{ ابهام نقش } \\
\hline TH.TETTEY & $.8 \wedge$ ४ \९q & r & \\
\hline rT.TFVATA & 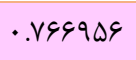 & r & \\
\hline rV.৭ৎ৭৭৭১ & $\cdot V \& V Y \cdot q$ & f & \\
\hline T.११VTFV & - VqVETV & $\Delta$ & \\
\hline $1 \vee . q \cdot \wedge q q$. & .911919 & 4 & \\
\hline$\Delta 9.9 \cdot 94 \mathrm{TI}$ & - . AFr^g. & v & \multirow{5}{*}{ اضافهبار نقش } \\
\hline A. $9 \vee \backslash \wedge r$ & 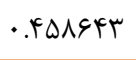 & $\wedge$ & \\
\hline FI.VITATr & 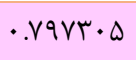 & 9 & \\
\hline TH.TETYGF & $.8 \wedge$ ४ & 1. & \\
\hline$V \cdot . r \& \& \Delta q 9$ & - AfIF.. & 11 & \\
\hline A.FYAVYI & - $\Delta V F \Delta \& q$ & ir & \multirow{4}{*}{ تعارض نقش } \\
\hline$\forall \vee \cdot \Lambda \cdot \Lambda ૬ ૬ V$ & . & Ir & \\
\hline 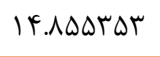 & G & If & \\
\hline$\checkmark . \cdots 111 \Lambda$ & - FTVD.D & 10 & \\
\hline
\end{tabular}

جدول r. نتايج تحليل عاملى تأييدى متغير سلامت روان كاركنان

\begin{tabular}{|c|c|c|c|}
\hline \multicolumn{2}{|c|}{ تحليل عاملى تأييدى } & \multirow{2}{*}{ سؤال } & \multirow{2}{*}{ متغير } \\
\hline t-value & بار عاملى & & \\
\hline$r r_{.} \cdot r \cdot \cdot r r$ & - VETTD. & 1 & \multirow{7}{*}{ علائم جسمانى } \\
\hline 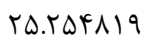 & - VAFEFT & r & \\
\hline$r \Delta . \wedge F q r \cdot r$ & •.VI9HIV & $r$ & \\
\hline TF.FYVA•D & ·. $1 . r q \mu V$ & r & \\
\hline TT.V.GKTI & -VTYATI & $\Delta$ & \\
\hline$r \cdot r V \cdot r r q$ & $\cdot . \backslash \wedge \vee \cdot G$ & 4 & \\
\hline 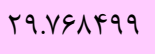 & •. V৭८।rq & V & \\
\hline rq.1.qF^r & $\cdot \wedge I \vee I V \wedge$ & $\wedge$ & \multirow{7}{*}{ اضطراب } \\
\hline$|\Delta . \Delta r \varepsilon| \cdot r$ & $.9091 \mathrm{rV}$ & 9 & \\
\hline rT.q.rFTr & $\cdot V \cdot I V \Delta F$ & 1. & \\
\hline$r . \wedge 9 \Delta \cdot r \Delta$ & -VAGKFI & 11 & \\
\hline $9.8 T \cdot Y \wedge r$ & - DVTrqR & ir & \\
\hline |S.FVIGHG & $.9 \vee \wedge 110$ & Ir & \\
\hline 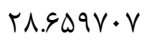 & - VVAIEF & If & \\
\hline $19.951 \cdot V 9$ & •.994VII & 10 & \multirow{4}{*}{ اختلال عملكرد اجتماعى } \\
\hline $9.94 \cdot \wedge r v$ & - FDIrFq & 19 & \\
\hline $19 . \vee \cdot \vee \wedge \Delta q$ & - grFIrA & IV & \\
\hline र1.99V199 & $\cdot \wedge \cdot \wedge r \varepsilon \wedge$ & 11 & \\
\hline
\end{tabular}




\begin{tabular}{|c|c|c|c|}
\hline \multicolumn{2}{|c|}{ تحليل عاملى تأييدى } & \multirow{2}{*}{ سؤال } & \multirow{2}{*}{ متغير } \\
\hline t-value & بار عاملى & & \\
\hline |N.|FrgDA & - VVATKV & 19 & \multirow{10}{*}{ افسردخى } \\
\hline N.MFFIFI & - VrqRVT & $r$. & \\
\hline $0.9 \wedge 9 \vee \backslash \Delta$ & $.9 \Lambda I V H F$ & TI & \\
\hline$|\Lambda . r \cdot \Lambda T V|$ & - . $1.9 T T V$ & Tr & \\
\hline$\Delta G . V F F \cdot r r$ & - $11 \cdot r V K$ & r & \\
\hline$r r .|9 \cdot r|$ & -VRTIVT & TF & \\
\hline rV.৭९१৭९८ & $\cdot . V G V H \cdot q$ & $T \Delta$ & \\
\hline Fq...vq. & $\cdot . V q \cdot r V r$ & Tq & \\
\hline $1 v . q \cdot \wedge q 4$. & .911919 & TV & \\
\hline$\Delta G . G \cdot q \times T$ & - AFT人G. & rA & \\
\hline
\end{tabular}

\begin{tabular}{|c|c|c|c|}
\hline \multicolumn{2}{|c|}{ تحليل عاملى تأييدى } & \multirow{2}{*}{ سؤال } & \multirow{2}{*}{ متغير } \\
\hline t-value & بار عاملى & & \\
\hline V.TIYqG & - YAT.NT & 1 & \multirow{12}{*}{ حمايت شغلى } \\
\hline rT.TQTVVD & - ATIAVD & r & \\
\hline DI.TTQTrV & $.9 T \mid V T 1$ & r & \\
\hline TI.MFFqGV & 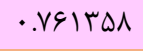 & f & \\
\hline FI.VITSHT & $\cdot . \vee q \vee r \cdot \Delta$ & $\Delta$ & \\
\hline TH.TERTEY & $.8 \wedge$. & 4 & \\
\hline$V \cdot r \varepsilon r \varepsilon \Delta q$ & $. A F \mid F$. & $\checkmark$ & \\
\hline$r \cdot r \cdot r g \cdot r$ & . FА१Vนr & $\wedge$ & \\
\hline$\& V \cdot \Lambda \cdot \wedge \& \& V$ & ·. & 9 & \\
\hline 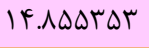 & . G. FrTE & $1 \cdot$ & \\
\hline$v . \cdots 1111$ & $\cdot . K Y V \Delta \cdot \Delta$ & 11 & \\
\hline r.q.. SVT & $\cdot \Delta r \cdot \wedge r \cdot$ & it & \\
\hline
\end{tabular}

\begin{tabular}{|c|c|c|c|}
\hline t-value & بار عاملى & سؤال & متغير \\
\hline A.FAFATV & DFTHE. DFT & 1 & \multirow{6}{*}{ كنترل روش } \\
\hline 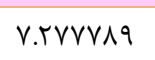 & $\cdot \Delta r \cdot F \psi g$ & r & \\
\hline IT.AVVAVF & . ETYFYT & r & \\
\hline 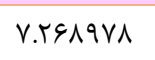 & - DTTGTF & r & \\
\hline MA.T.FTIF & . VIFrg. & $\Delta$ & \\
\hline 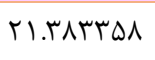 & . VTYKGK & 4 & \\
\hline$|r . r F f| \cdot \Delta$ & . gDFrqT & V & \multirow{4}{*}{ كنترل زمان } \\
\hline 19.r.rTQF & - VTSNIT & $\wedge$ & \\
\hline Tr.METHIF & - VGT. FT & 9 & \\
\hline 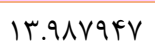 & $\cdot .9 \Lambda \cdot \Lambda \cdot V$ & 1. & \\
\hline
\end{tabular}


ناكفته نماند مقدار AVE براى متغيرهاى مكنون بيشتر از \&/· بود؛ بنابراين، مىتوان كَفت روايى همكراى مدلهاى اندازمخيرى

جدول 9. مقادير روايى همكرا

\begin{tabular}{|c|c|}
\hline روايى همثرا & متغير \\
\hline$\cdot .+\cdot q v<\Delta$ & ابهام نقش \\
\hline$\cdot V Y F \Delta A V$ & اضافهبار نقش \\
\hline$\cdot . v \cdot \mid \Delta V \wedge$ & تعارض نقش \\
\hline $.01 \% \cdot+4$ & علائم جسمانى \\
\hline$. V 99 \mid Y I$ & اضطراب \\
\hline . DVQTYT & اختلال عملكرد اجتماعى \\
\hline$\cdot . \varphi \Delta l \cdot \Delta \Delta$ & افسردىى \\
\hline . GATYTr & حمايت شغلى \\
\hline$\cdot . \Delta q \lambda F \cdot F$ & كنترل روش \\
\hline$\cdot$. VAYVYI & كنترل زمان \\
\hline
\end{tabular}

\section{"إيايى ابزار اندازهتيرى}

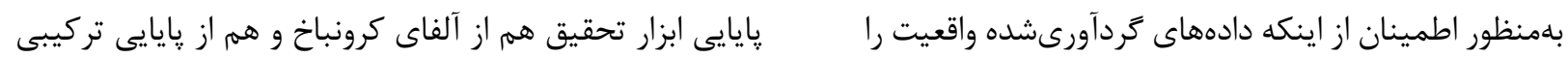

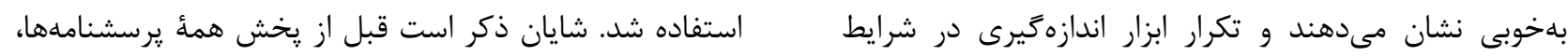

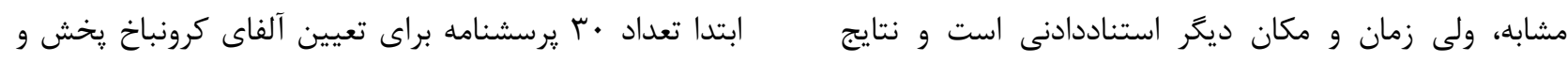

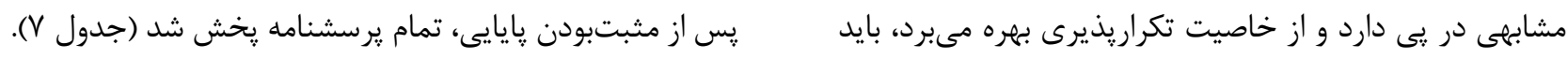

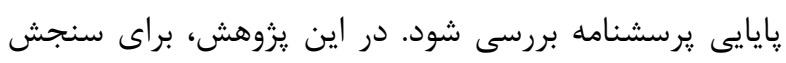

جدول V. ضرايب آلفاى كرونباخ

\begin{tabular}{|c|c|}
\hline ضريب آلفاى كرونباخ & متغير \\
\hline$\cdot .9 T \cdot(r) \cdot$ & ابهام نقش \\
\hline 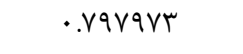 & اضافهبار نقش \\
\hline •.VYYAVI & تعارض نقش \\
\hline$\cdot .1490 \cdot 9$ & علائم جسمانى \\
\hline$\cdot . V 1 \cdot q r F$ & اضطراب \\
\hline . ANFKG. & اختلال عملكرد اجتماعى \\
\hline - VDFVqR & افسردگى \\
\hline$\cdot . \vee G \cdot \wedge r \wedge$ & حمايت شغلى \\
\hline - Vrव८१९ & كنترل روش \\
\hline 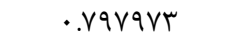 & كنترل زمان \\
\hline
\end{tabular}

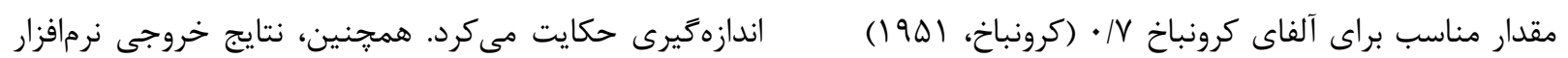

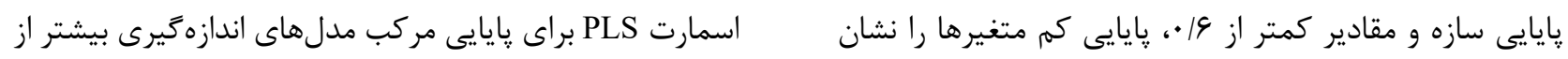

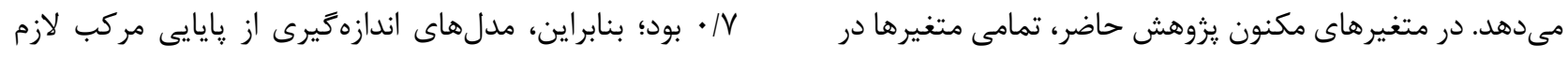

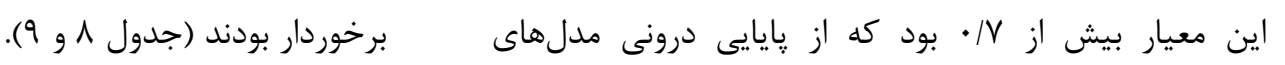


داده شده است، ضرايب معنادارى بيش از 199/ بود كه مىتوان

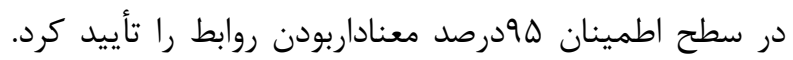

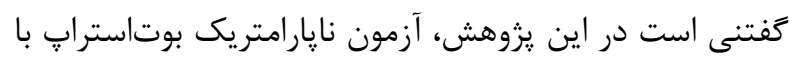

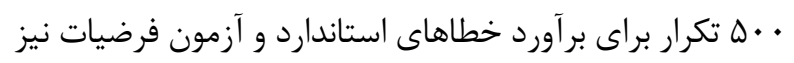

\section{ضرايب معنادارى Z (مقادير t-values)}

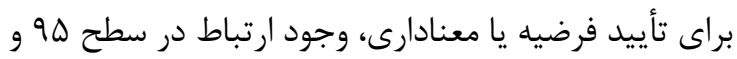

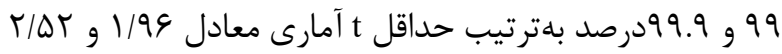

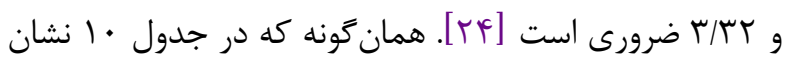

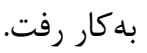

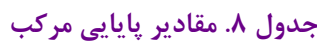

\begin{tabular}{|c|c|}
\hline يايايى تركيبى & متغير \\
\hline$\cdot . \wedge \varepsilon \Delta \mid \vee$. & ابهام نقش \\
\hline - . AF\&qDI & اضافهبار نقش \\
\hline$\cdot . \Lambda \Lambda \cdot G Y \Lambda$ & تعارض نقش \\
\hline$\cdot . \Lambda F \cdot T \Lambda F$ & علائم جسمانى \\
\hline ·.AVDIrq & اضطراب \\
\hline$\cdot . \wedge \& \Delta \mid \vee \cdot$ & اختلال عملكرد اجتماعى \\
\hline - $.1 F F q D 1$ & افسردگى \\
\hline$\cdot . \Lambda F \cdot T \Lambda F$ & حمايت شغلى \\
\hline · AvDIrq & كنترل روش \\
\hline$\cdot . V r q 1 \cdot 1$ & كنترل زمان \\
\hline
\end{tabular}

جدول 9.

\section{تعداد (درصد)}

$(T \Delta . \Lambda) M F$

(Fr.q) $\Delta \Lambda$

$(r \cdot r) \varphi \cdot$

$(r \cdot)^{4}$

(9.1) Ir

(VD.•) 99

(Ir.q) TV

(TF.T) TY

(YF.T) TY

(19.V) Tr

(YT.V) T.

(IT.1) 19

\section{متغير}

سن

اب تا • ع سال

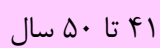

دييلم

فوقديِلمم

ليسانس

تحصيلات

فوقليسانس و عالىتر

كمتر از هال سال

ع تا • ال سال

| 1 تا هال سال

19 تا • r سال

بيش از ال سال

جدول •ا. ضرايب معنادارى Z (مقادير t-values) براى متغيرهاى مكنون درونزا

\begin{tabular}{|c|c|c|}
\hline سطح اطمينان & 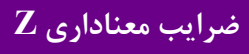 & سير \\
\hline 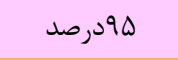 & $11.1 \mathrm{Fa}$ & تغيير سازمانى بر سلامت روان كاركنان \\
\hline ه9 مدرصد & T.^ৎ & تغيير سازمانى با درنظرگرفتن اثر تعديلكر حمايت شغلى بر سلامت روان كاركنان \\
\hline 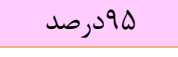 & $1 \cdot \cdot r$ & تغيير سازمانى با درنظركرفتن اثر تعديلكر كنترل شغلى بر فرسودىى كاركنان \\
\hline
\end{tabular}




\section{شاخص افزونكى v}

اين شاخص معيار سنجش كيفيت مدل ساختارى براى هر بلوى آزيى

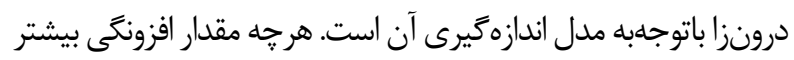

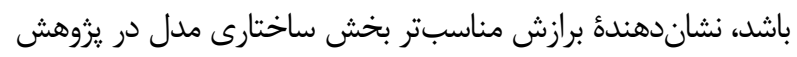

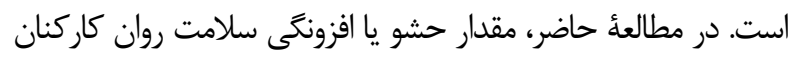

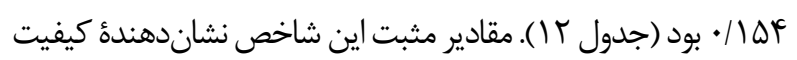

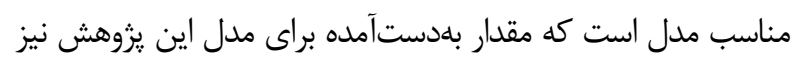
مؤيد اين موضوع بود [بr] مبت.

\section{ضريب تعيين}

معيار اساسى براى ارزيابى متغيرهاى مكنون درونزا، ضريب تعيين

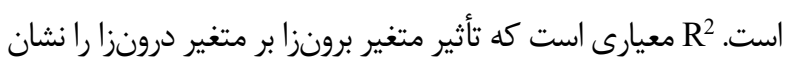

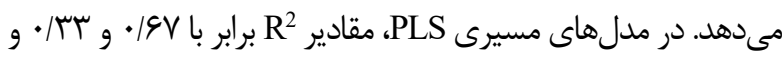

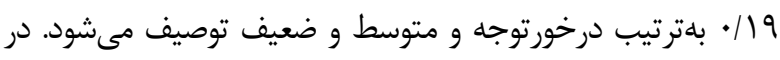

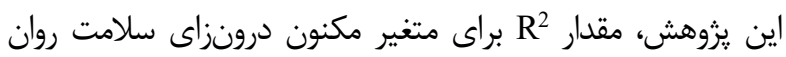

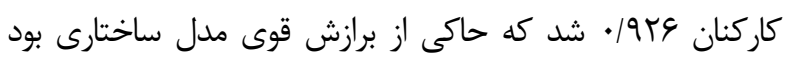

(جدول (1).

جدول Iا. مقادير ضريب تعيين براى متغيرهاى مكنون درونزا

ضريب تعيين

. 1949
ابعاد و مؤلفهها

سلامت روان كاركنان

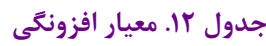

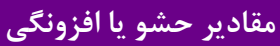

- /lQf

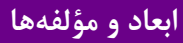

سلامت روان كاركنان

متغيرهاى مستقل آنها ارتباط ييشبين دارند. اثر نسبى ارتباط ارتباط يِيشبين

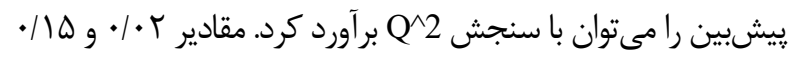

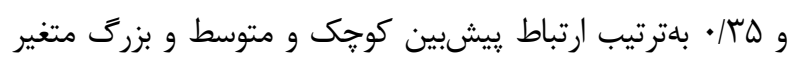

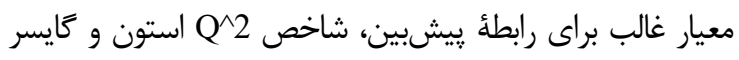
مكنون معين را نشان مىدهند. Q22 كمتر از صفر فقدان ارتباط

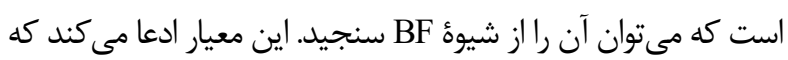
مدل بايد بتواند يِشبينىاى از معرفهاى متغير مكنون درونزا ارائه

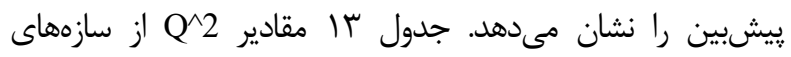
درونزاى مدل حكايت مى كند كه نشاندهنده قدرت بيشيثين رينى اين

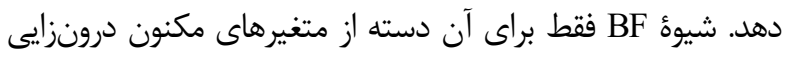
مدل براى سازء كنترل شغلى و متوسط براى ساير سازههاست و برازش مدرن به كار مىرود كه بهصورت مدل اندازهيرى انعكاسى عملياتى شدهاند. اكر اين مقدار براى متغير مكنون درونزاى معين بيشتر از صفر باشد،

$$
\text { مناسب مدل ساختارى را تأييد مى كند. }
$$

\section{جدول با. ارتباط يِيشبين}

\begin{tabular}{|c|c|c|}
\hline قدرت بيشبينى & معيار بيشبين & ابعاد و مؤلفهها \\
\hline متوسط & D & تغيير سازمانى \\
\hline متوسط & $\cdot 111$ & سلامت روان \\
\hline متوسط & $\cdot / 1 \mathrm{~V}$ & حمايت شغلى \\
\hline قوى & $\cdot / \mu$ & كنترل شغلى \\
\hline
\end{tabular}

\section{معيار ارزيابى برازش كلى مدل}

به بيشبينى كرايش دارند؛ بنابراين، روايى مدل عمدتاً بر قابليت

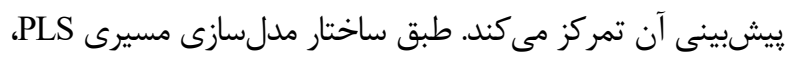

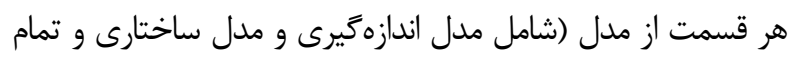

مدلسازى مسيرى PLS از معيار بهينهسازىشده كلى بى بهره

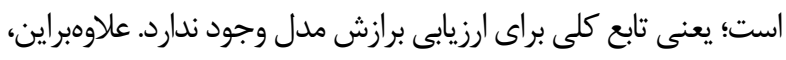
مدلهاى مسير PLS مدلهايى مبتنىبر واريانس هستند كه بلهدت برات 


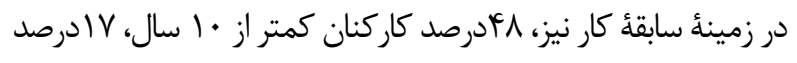

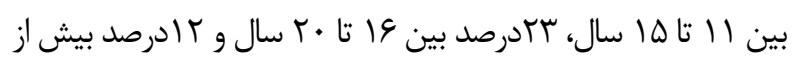
ا Tال سابقه داشتند.

\section{آزمون فرضيات}

الخوريتم تحليل دادهها در روش PLS نشان مىدهد كه يس از بررسى برازش مدلهاى اندازهيرى و مدل ساختارى و مدل كلى،

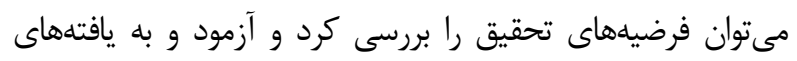

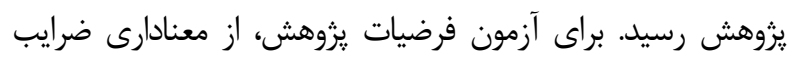

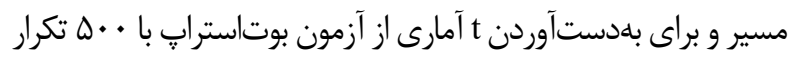

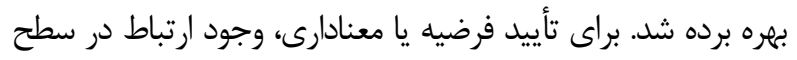

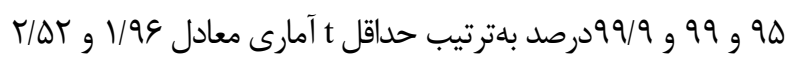

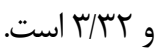

\section{ضريب مسير}

هر ضريب مسير در مدل ساختارى PLS را مىتوان معادل ضريب

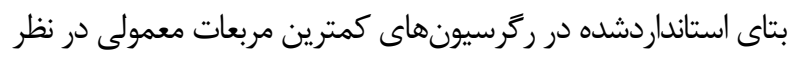
گرفت. مسيرهايى كه علامت جبرى آنها برخلاف انتظار است، فرضيات شكل مسير مدل ساختارى را مشاهده مى كنيد. بلطور كلى، انتظار مىرود در

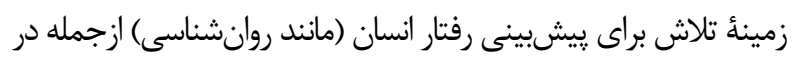

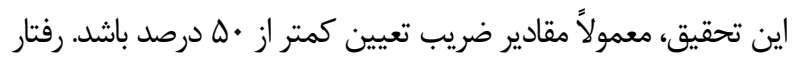

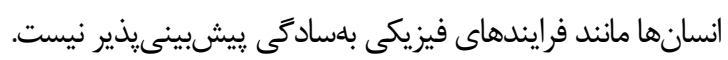

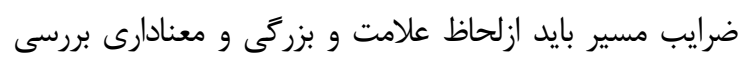

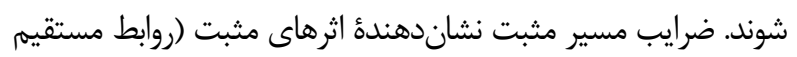

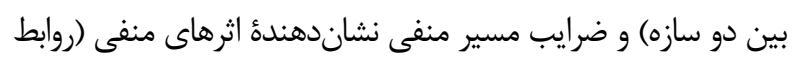

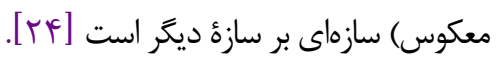

مدل) بايد بهينه شود؛ بههميندليل در مدلسازى مسيرى PLS در اين تحقيق، شاخص نيكويى برازش (GOF) براى تناسب مدل ارائه شد.

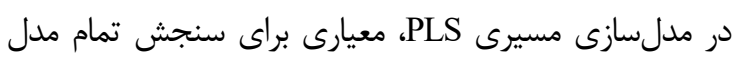

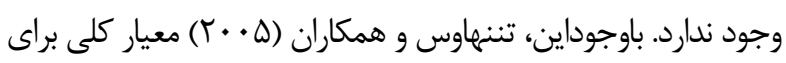

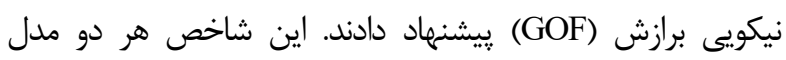

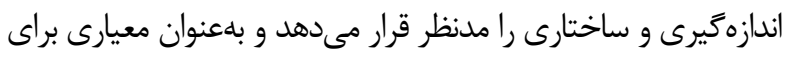

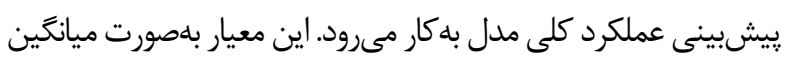
هندسى R2 و متوسط اشتراك محاسبه مىشود:

$$
G O F=\sqrt{\text { communality }} \times \overline{R^{2}}
$$

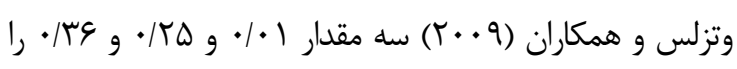
بلعنوان مقادير ضعيف و متوسط و قوى براى GOF معرفى كردهاند؛ بنابراين، مقدار نيكويى برازش براى مدل بررسىشده برابر بود با:

$$
\mathrm{GOF}=\sqrt{0.54171 * 0.709}=0.384
$$

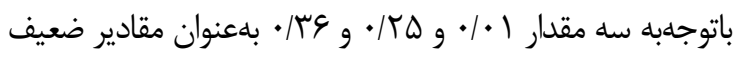
و متوسط و قوى براى GOF، مقدار بdدستآمده براى GOF نشاندهنده برازش كلى قوى مدل براى يزوهش حاضر بود.

بافته ها

همان Fونه كه در جدول r مشاهده مي كند، ع بردصد از كاركنان

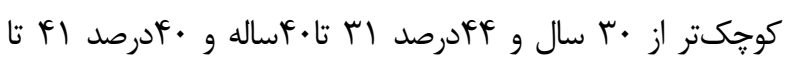
•هساله بودند. همجنين، "ادرصد آنان دييلم، 9 •درصد فوقدييلم، VVDرصد ليسانس و سا ادرصد مدرك فوقليسانس و عالىتر داشتند.

جدول fl. ضرايب مسير ساختارى

ضرايب مسير

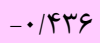

$\cdot$ ret

. / 9 V

\section{مسير}

تغيير سازمانى بر سلامت روان كاركنان

تغيير سازمانى با درنظركرفتن اثر تعديلكر حمايت شغلى بر سلامت روان كاركنان

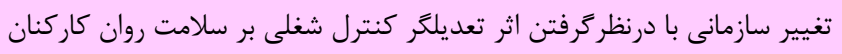

\section{بحث و نتيجه گيرى}

هنگامى روى مىدهد كه نقشهاى كارى بلهورمتناوب در رقابتى نامناسب باشند يا كاركنان در وضعيت نامناسبى فعاليت كنند؛ مثلاً فردى كه كارش با باورهاى شخصى ناش در در تضاد

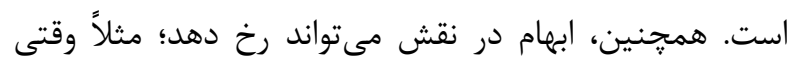

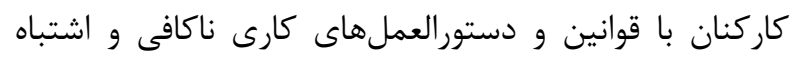

باتوجهبه فرضئُ اول يزوهش، مىتوان كفت كه تغيير سازمانى بر سلامت روان كاركنان بيمارستان فرشجيان (سينا)

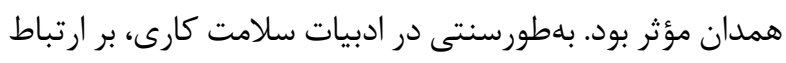

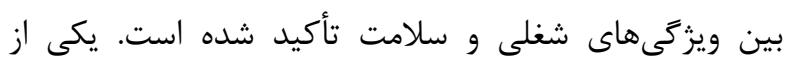
مفاهيم بررسىشده در اين زمينه، تعارض نقش است. تعارض 
روانى مؤثر است. اكر شغل فرد با استرس همراه باشد؛ اما فرد

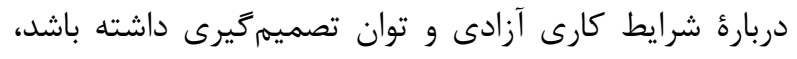

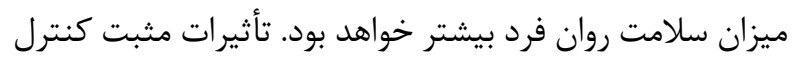
بر روشهاى انجام كار در صورتى مؤثر است كه كاركنان اين فئن

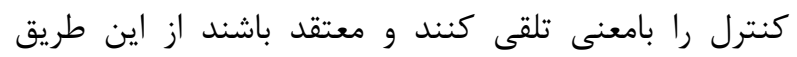
مجموعهاى از مهارتهايشان در كار استفاده مىشود و واحساس

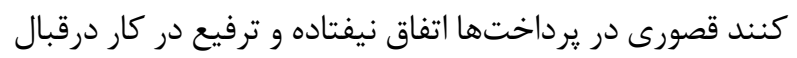

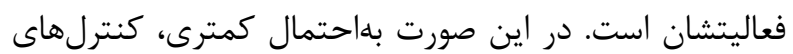

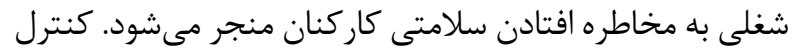

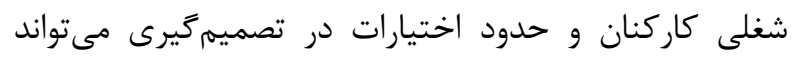
كاهش و تعديل تنشهاى شغلى را سبب شود. امروزه، حدود

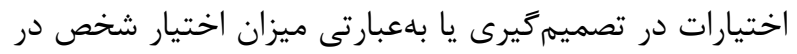

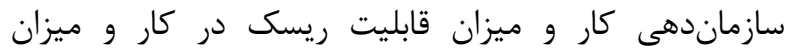

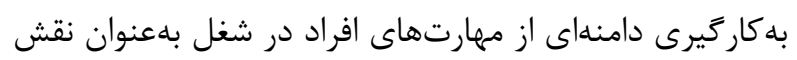

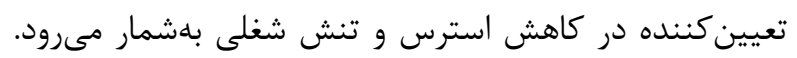
در محيطهاى كارى كه حدود اختيارات كاركنان بسيار است،

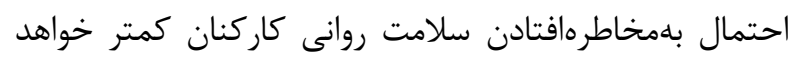
بود. درمقابل، در محيطهاى كارى كه حدود اختيارات كاركنان

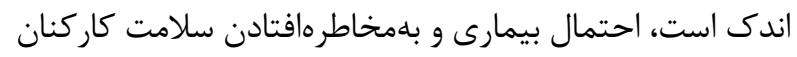

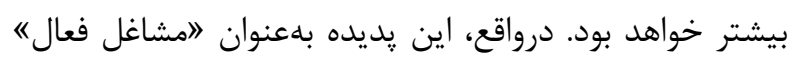

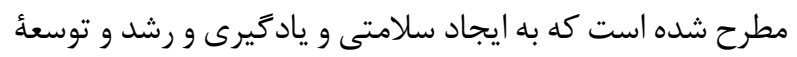
فردى منجر مىشود. - براساس تحليل مسير انجامشده، قوىترين رابطهٔ مستقيم و مثبت علّى ميان مؤلفههاى مدل، تأثير مستقيم و معنادار تغيير سازمانى بر سلامت روان كاركنان بود (ضريب استاندارد: צ بع/•).

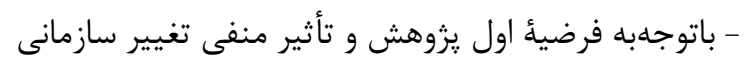

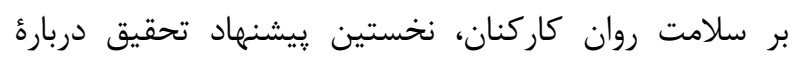

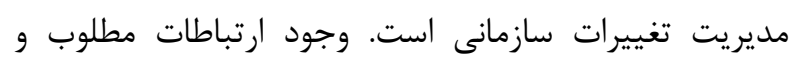

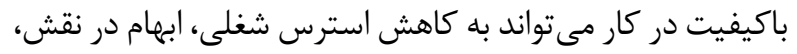
افزايش رضايت شغلى و بهبود عملكرد و سلامت روان كاركنان

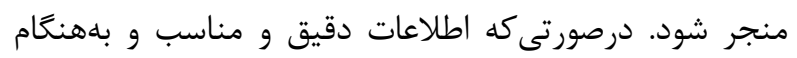
دربارئ تغييرات سازمانى به كار كنان داده شود، اين احتمال كمتر

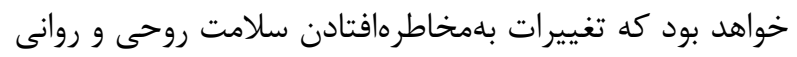

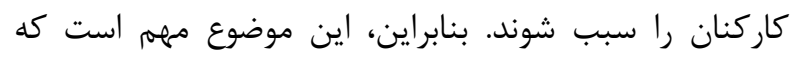

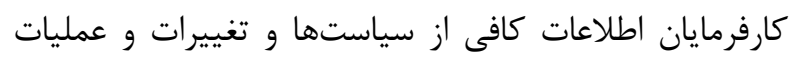

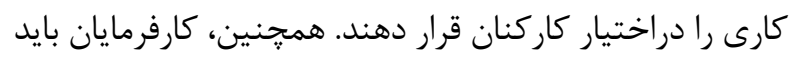

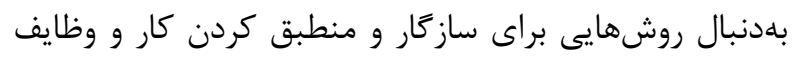

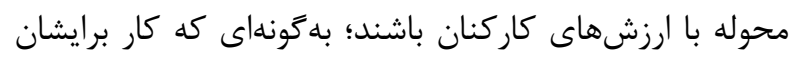

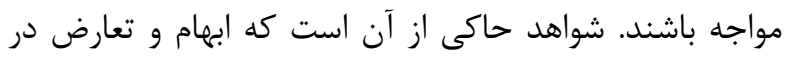

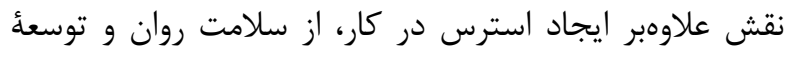

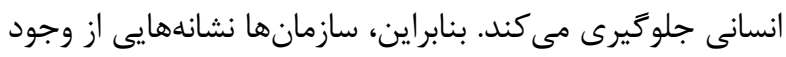

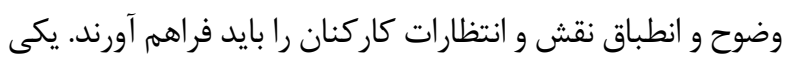

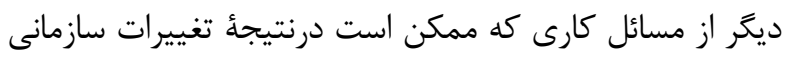

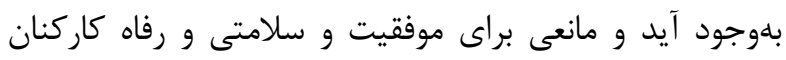

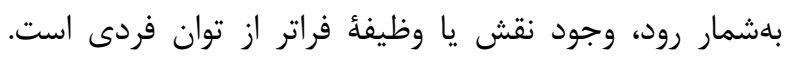
و Rafferty بازسازى و ادغام مىتواند به استرس بيشتر كاركنان منجر شود

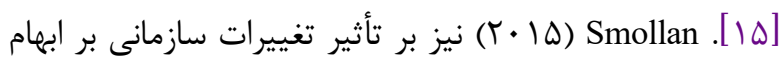

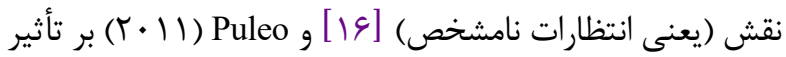

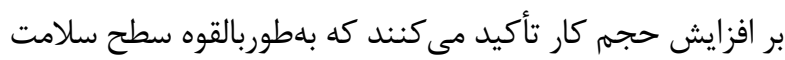

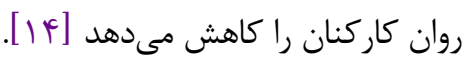

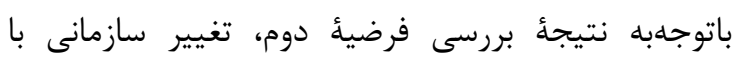

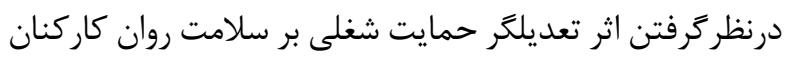

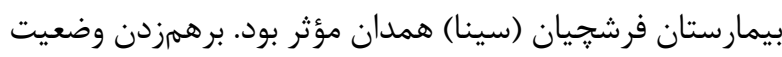

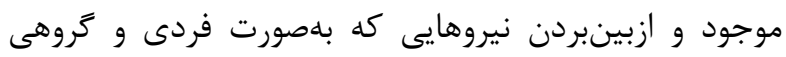

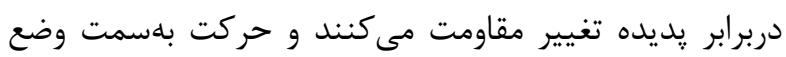
جديد كه بهمعناى تغيير سازمانى است، مىتواند موجب ايجاد

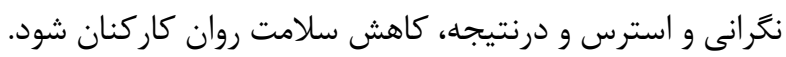

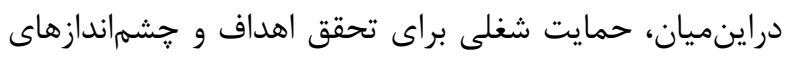

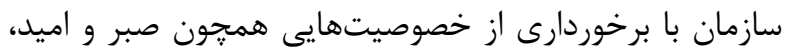

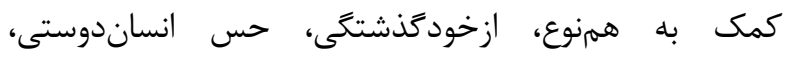

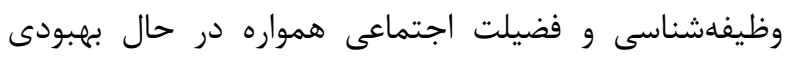
سيستمها و فرايندهاى كارى است و مىتواند از كاهش سلامت

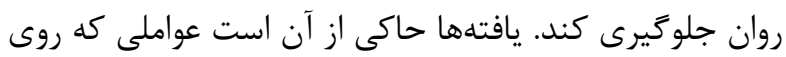

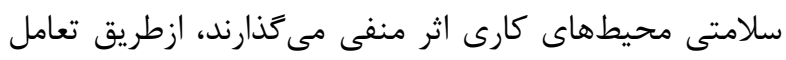

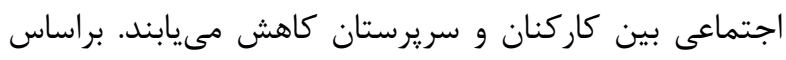

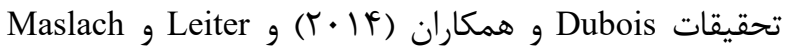

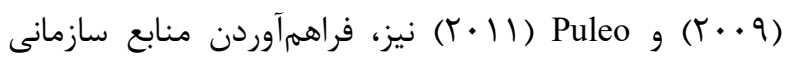

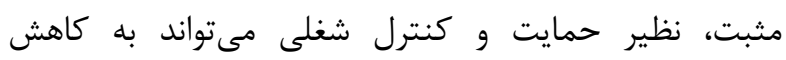

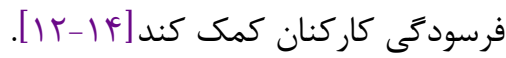

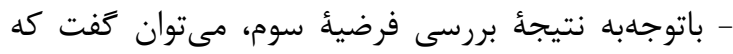

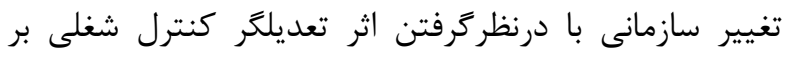
سلامت روان كاركنان بيمارستان فرشجيان (سينا) همدان

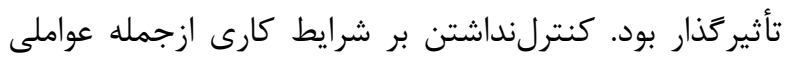

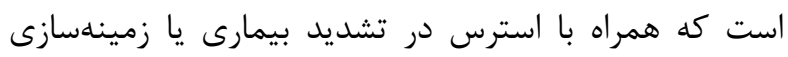

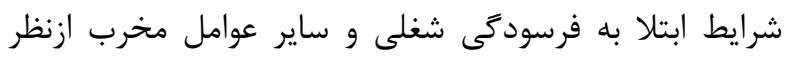


بخشها به يكديخر، مرزهاى نفوذيذير دربرابر ايدها و ارتباط نزديك مديران با كاركنان بهدليل اهداف سازمانى، براى داشت داشتن

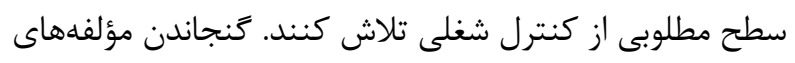

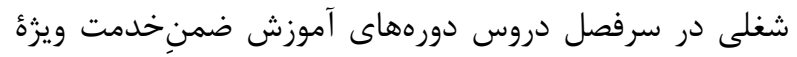

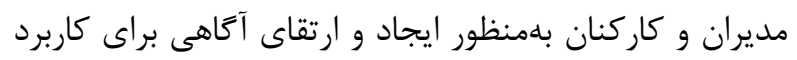

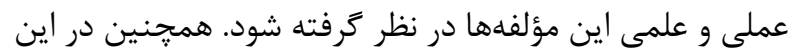

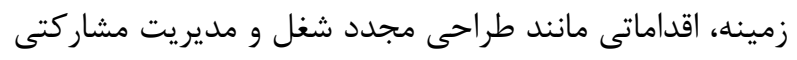

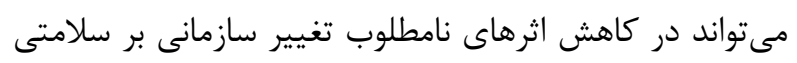

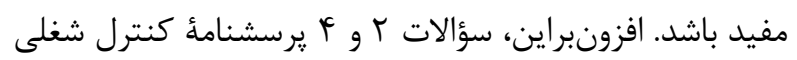

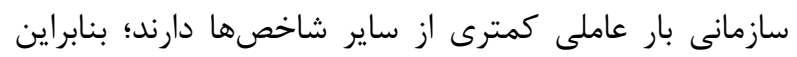

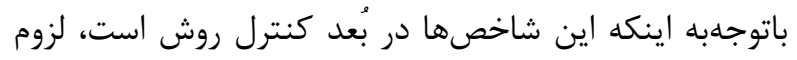

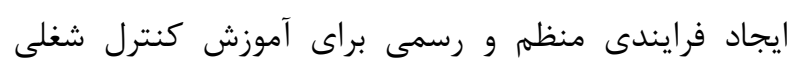

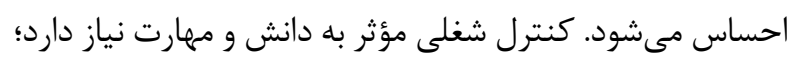

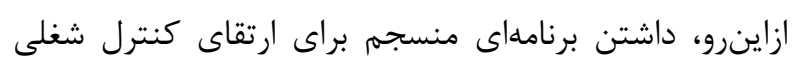

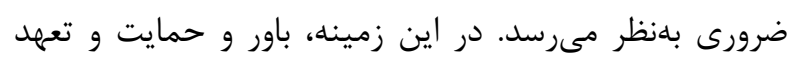

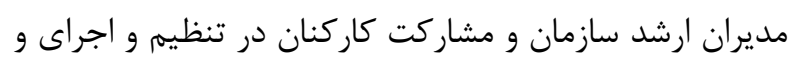
ارزيابى اين برنامهٔ تغيير و تحول ضرورى است.

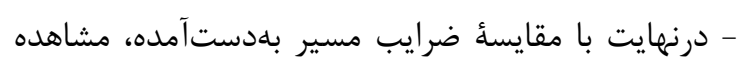

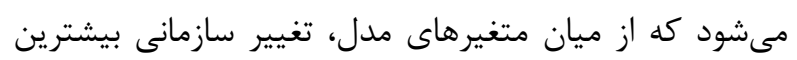

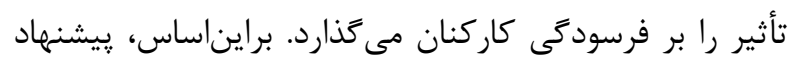

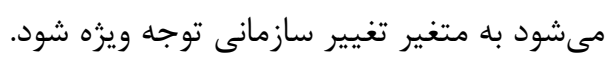

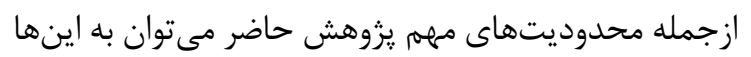

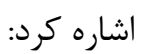

1. كمبود تحقيقات داخلى و خارجى مرتبط با موضوع

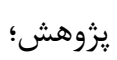

آ. كنترلنشدن متغيرهاى مزاحم، ازجمله سطح فرهنكى و

اجتماعى و روانشناختى كاركنان بر ميزان سلامت روان آنان.

\section{تقدير و تشكر}

مطالعئ حاضر بركرفته از يايان نامهاى با عنوان \اتأثير تغيير

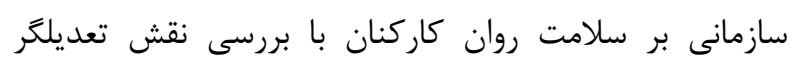

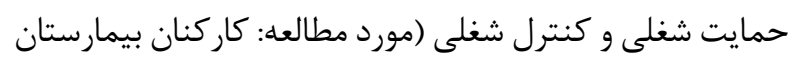

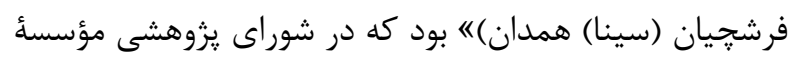

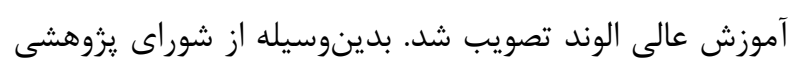

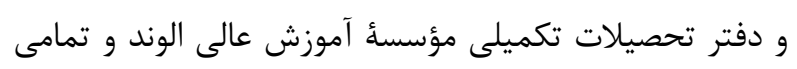

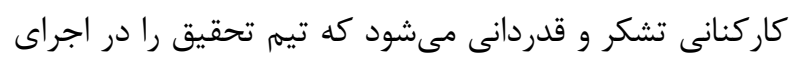

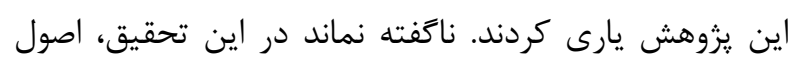

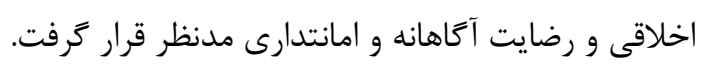

بامعنى باشد. كارهاى تكرارى و خستهكننده به بيمارى و

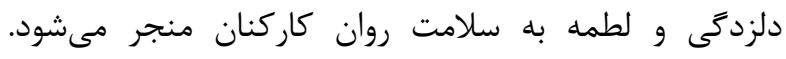

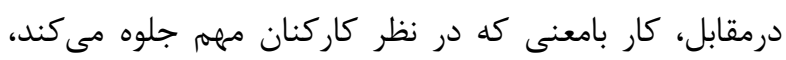

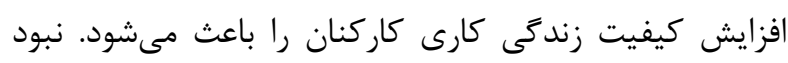

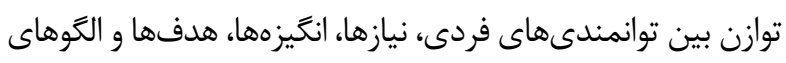

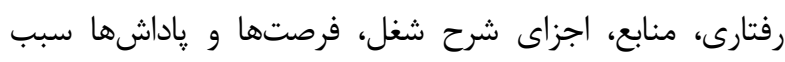

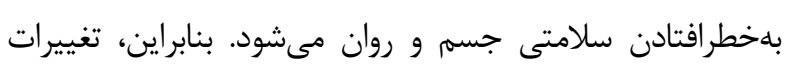

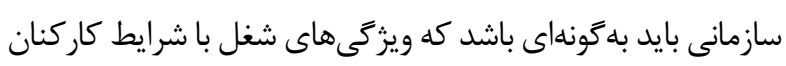

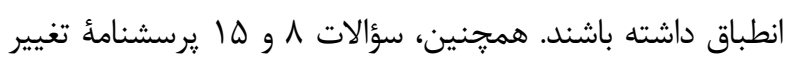

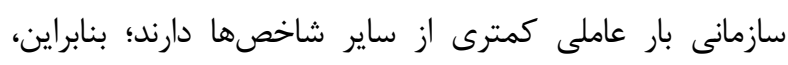

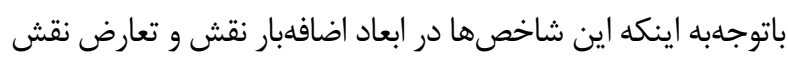

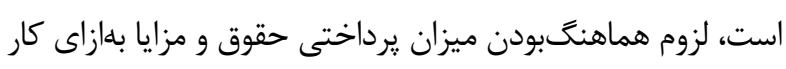

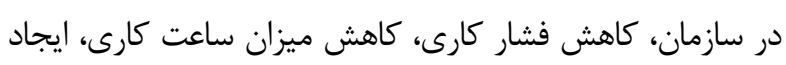

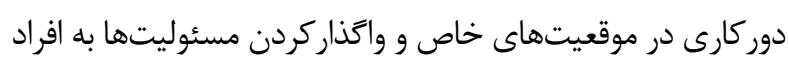
مطابق با ظرفيت آنان بسيار اهميت داردي

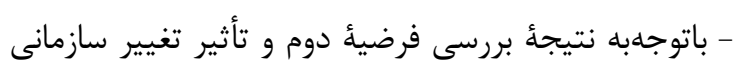

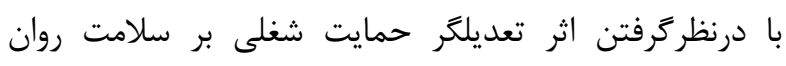

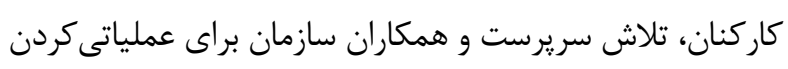

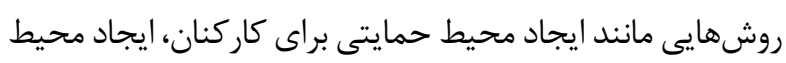

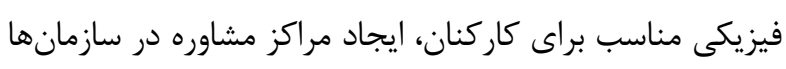

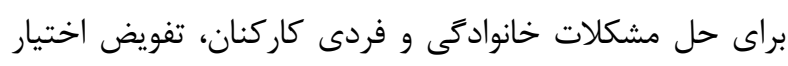

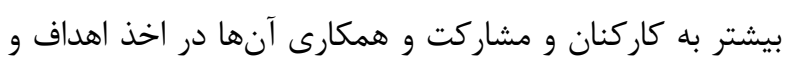

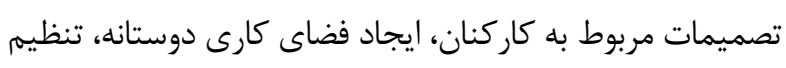

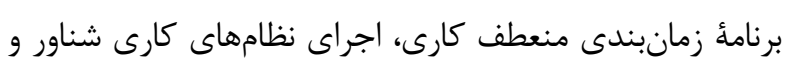

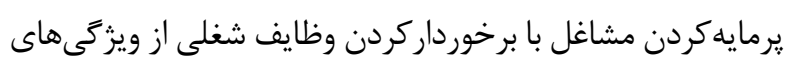

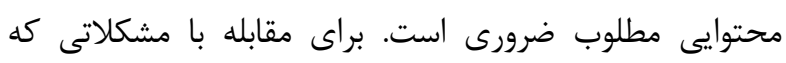

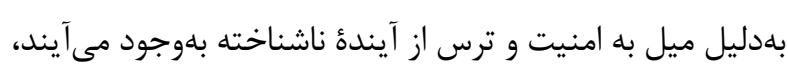

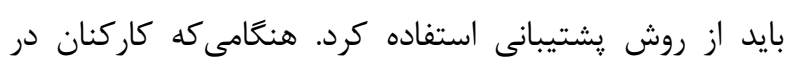

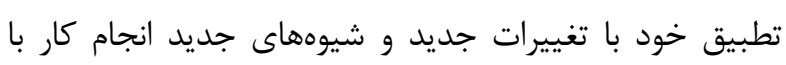

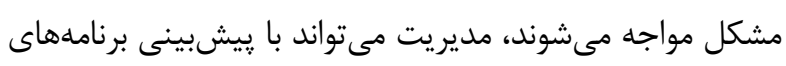

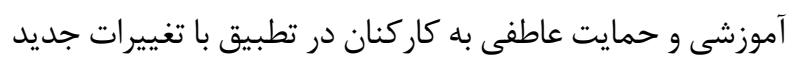

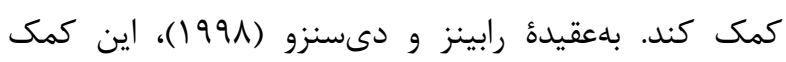

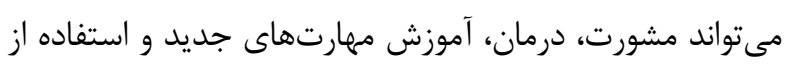
مرخصى با حقوق به مدتى كوتاه باشد. باتوجلبه نتيجأ بررسى فرضئ سون سوم و تأثير تغيير سازمانى

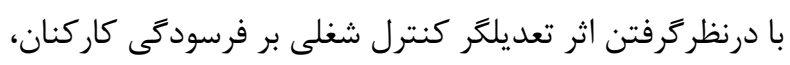

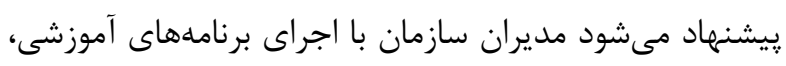

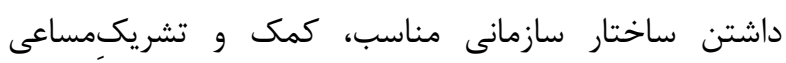




$$
\text { تجارى وجود ندارد و نويسند مان درقبال ارائٔ اثرشان وجهى منابى }
$$

\section{References}

1. Sanagoo A, Behnampour N, Taghavee A, Baiky F. Relationship between mental health and burnout in Al-E-Jalil Hospital's staff, 2014. J Res Dev Nurs Midw. 2015; 12(2): 21-8.

2. Dastgheib Z, Ghobadi Dashdebi K, Gharlipour Gharghani Z, Hoseini F, Babaei Heydarabadi A, Ashrafi Hafez A. Investigation of correlation between mothers' marital satisfaction and depression among their adolescent in Shiraz. Adv Nurs Midw. 2015; 24(84): 19-26.

3. Asadzandi M, Sekarifard M, Ebadi A, Morovvati Sharif Abad MA, Salari M. Effects of anger management training based on Health Promotion Model on soldiers engaged in risky behavior. J Nurs Educ. 2015; 2(4): 68-79.

4. Sabbagh S, Moeinian N, Sabbagh S. The assessment of the social factors associated with social health of families in Tabriz. Sci J Manag Syst. 2011; 3(10): 27-44.

5. Pishvae M, Kohneshin A, Pishvae V, Meshki M. The importance of mental health in the family. National Conference on Psychology and Social Injury Management. Iran, Chabahar: Islamic Azad University, Chabahar Branch; 2015.

6. Hosseini Z, Hazavehei MM, Imanzad M, Ghanbarnezhad A, Gharlipour Z. Occupational stress and mental health relationship in nurses. Adv Nurs Midw. 2014; 23(2):55-62.

7. Anderson DL. Organization development: The process of leading organizational change. New York: SAGE Publications; 2019.

8. Barbaroux P. A design-oriented approach to organizational change: Insights from a military case study. J Organ Chang Manag. 2011; 24(5): 626-639. [DOI:10.1108/09534811111158895]

9. Bourbonnais R, Brisson C, Malenfant R, Vézina M. Health care restructuring, work environment, and health of nurses. Am J Ind Med. 2005; 47(1): 54-64. [DOI:10.1002/ajim.20104] [PMID]

10. Rahimnia F, Hasanzadeh Zhaleh F. The impact of job burnout on the dimensions of denison's organizational culture. Modiriyat-e Farda. 2013; 11(33): 129-43.

$$
\begin{aligned}
& \text { تعارض منافع } \\
& \text { هيجز گونه تعارض منافعى در تهيئ دادهها و اطلاعات اوليه و } \\
& \text { نهايى و نتايج حاصل از يزوهش بين نكارندكان و سازمان } \\
& \text { مطالعهشده وجود ندارد. نخارند } \\
& \text { انتشار مقالهٔ ارائهشده، از سرقت ادبى، سوءرفتار، جعل دادهها يا }
\end{aligned}
$$

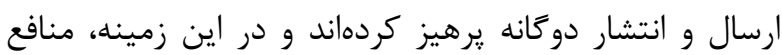

11. Hylton J, editor Leadership: The next HHR crisis? Part I. Healthcare management forum. Los Angeles, CA: SAGE Publications; 2004. [DOI:10.1016/S0840-4704(10)60308-0]

12. Dubois CA, Bentein K, Ben Mansour J, Gilbert F, Bdard JL. Why some employees adopt or resist reorganization of work practices in health care: associations between perceived loss of resources, burnout, and attitudes to change. Int J Environ Res Public Health. 2014; 11(1): 187-201. [DOI:10.3390/ijerph110100187] [PMID] [PMCID]

13. Leiter MP, Maslach C. Nurse turnover: the mediating role of burnout. J Nurs Manag. 2009; 17(3): 331-39. [DOI:10.1111/j.13652834.2009.01004.x] [PMID]

14. Puleo G. Causes and maintenance factors of employee burnout during transformational organizational change. Walden University; 2011.

15. Rafferty AE, Griffin MA. Perceptions of organizational change: A stress and coping perspective. J Appl Psychol. 2006; 91(5): 1154-62. [DOI:10.1037/0021-9010.91.5.1154] [PMID]

16. Smollan RK. Causes of stress before, during and after organizational change: A qualitative study. J Organ Chang Manag. 2015; 28(2): 301-314. [DOI:10.1108/JOCM-03-2014-0055]

17. Day A, Crown SN, Ivany M. Organisational change and employee burnout: The moderating effects of support and job control. Saf Sci. 2017; 100: 4-12. [DOI:10.1016/i.ssci.2017.03.004]

18. Shahnazdoust M, Maghsudi SH, Tabari R, Kazemnegad E. Relationship between Nursing Burnout and Occupational support. J Guilan Univ Med Sci. 2012; 20(80): 49-59.

19. Turner N, Stride CB, Carter AJ, McCaughey D, Carroll AE. Job Demands-Control-Support model and employee safety performance. Accid Anal Prev. 2012; 45: 811-17. [DOI:10.1016/j.aap.2011.07.005] [PMID]

20. Sterling M. General health questionnaire-28 (GHQ28). J physiother. 2011; 57(4): 259. [DOI:10.1016/S1836-9553(11)70060-1] 
21. Zardoshtian S, Abbasi H, Esmaeili M, Khanmoradi $\mathrm{S}$. The relationship perceived organizational support, job involvement and organizational citizenship behavior of physical education teachers in Hamedan Province. Organ Behav Manag Sport Stud. $2015 ; 2$ (6): 93-103.

22. Naami A, Shenavar A. The role of work engagement, job control, innovative behavior, and transformational leadership in prediction of job crafting. Manag Res. 2015; 8(27): 145-65.

23. De Vente J, Poesen J, Arabkhedri M, Verstraeten G. The sediment delivery problem revisited. Prog Phys Geog. 2007; 31(2): 155-78 [DOI: 10.1177/0309133307076485]

24. Azar A, Gholamzadeh R, Ghanavati M. Routingstructural modeling in management: Application of smart PLS software. Tehran: NegahDanesh; 2011. 